\title{
Effect of chemokine CC ligand 2 (CCL2) on $\alpha$-synuclein-induced microglia proliferation and neuronal apoptosis
}

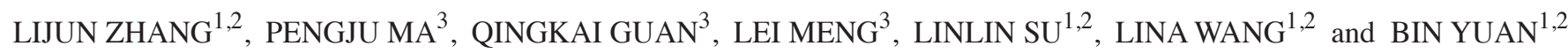 \\ ${ }^{1}$ Department of Neurology; ${ }^{2}$ Henan Key Laboratory of Neural Regeneration and Repairment; ${ }^{3}$ Department of Neurosurgery, \\ The First Affiliated Hospital of Xinxiang Medical University, Xinxiang, Henan 453000, P.R. China
}

Received October 15, 2017; Accepted June 29, 2018

DOI: $10.3892 / \mathrm{mmr} .2018 .9468$

\begin{abstract}
The present study aimed to investigate the effect of chemokine CC ligand 2 (CCL2) on $\alpha$-synuclein-mediated microglia proliferation and neuronal apoptosis. Primary cultured microglia and primary neurons were isolated and cultured in vitro. Microglia were divided into four groups: The cells in the control group were treated with an identical amount of PBS, whereas the cells in the CCL2 group were cultured in medium containing $0.05 \mathrm{ng} / \mu \mathrm{l}$ CCL2; cells in the $\alpha$-synuclein group were treated with medium containing $0.2 \mathrm{ng} / \mu 1 \alpha$-synuclein; and cells in the CCL2 plus $\alpha$-synuclein group were cultured in medium containing $0.05 \mathrm{ng} / \mu \mathrm{l}$ CCL2 and $0.2 \mathrm{ng} / \mu 1 \alpha$-synuclein. After incubation for $24 \mathrm{~h}$, the proliferation of glial cells, and the level of $\alpha$-synuclein in the cells, were measured. The levels of tumor necrosis factor- $\alpha$ (TNF- $\alpha$ ), interleukin-1 $\beta$ (IL-1 $\beta$ ) and nitric oxide (NO) in the culture medium were also measured. Levels of cleaved caspase-3, Akt and phosphorylated (p)-Akt in neurons treated with primary microglia culture medium in each group were subsequently monitored. The proliferation activity and secretion of TNF- $\alpha$, IL-1 $\beta$ and NO in the CCL2, $\alpha$-synuclein and CCL2 plus $\alpha$-synuclein groups were significantly higher compared with that in the control group $(\mathrm{P}<0.05)$, as were the levels of $\alpha$-synuclein $(\mathrm{P}<0.01)$. The levels of neuronal apoptosis and cleaved caspase-3 protein in the CCL2, $\alpha$-synuclein and CCL2 plus $\alpha$-synuclein groups were also significantly higher compared with that in the control group $(\mathrm{P}<0.01)$. Taken together, these results have demonstrated that CCL2 is able to promote $\alpha$-synuclein secretion and the apoptosis of neurons induced by $\alpha$-synuclein, thus inducing proliferation of the microglia and secretion of TNF- $\alpha$, IL-1 $\beta$ and NO.
\end{abstract}

Correspondence to: Dr Lijun Zhang, Department of Neurology, The First Affiliated Hospital of Xinxiang Medical University, 88 Jiankang Road, Xinxiang, Henan 453000, P.R. China E-mail: smith20081558@sina.com

Key words: microglia, neurons, chemokine CC ligand 2, apoptosis

\section{Introduction}

Microglia, a type of glial cell, is an important immune line of defence in the central nervous system. The effects of microglia in brain tissue and spinal cord are similar to those of macrophages (1). Of all the glial cells found in brain tissue, $20 \%$ are microglia (2). Microglia hyperproliferative activation is found in Alzheimer's disease, Parkinson's disease, and other diseases, and the overactivation of microglia has been shown to lead to neurotoxicity (3).

Chemokine CC ligand 2 (CCL2) is a member of the chemokine family, which is secreted by human vascular endothelial cells, astrocytes, microglia, smooth muscle cells, and other types of cell. CCL2 is able to regulate macrophage chemotaxis, the activation of basophils, as well as being involved in the processes of cell proliferation and apoptosis $(4,5)$. $\alpha$-synuclein is a type of nerve protein that is widely distributed in brain tissue, where it serves an important role in maintaining synaptic function (6). The over-aggregation of $\alpha$-synuclein leads to Lewy body dysfunction, triggering learning, memory and other functional deficiencies (7). A previous study has demonstrated that CCL2 may promote the proliferation of microglia, and also promote the secretion of inflammatory factors, thus leading to the toxicity produced by excessive aggregation of $\alpha$-synuclein (8). In the present study, microglia were used as the cell type of choice to investigate the role of CCL2 in $\alpha$-synuclein-mediated microglia proliferation and neuronal apoptosis, in order to provide a theoretical basis underpinning the development of therapies for treatment of neurological diseases.

\section{Materials and methods}

Materials. A total of 10 SPF C57/BL6 mice (5 female/5 male), aged 1-3 days and 200 $\pm 20 \mathrm{~g}$ in weight, were purchased from the Experimental Animal Center of Xinxiang Medical University (Xinxiang, China). All animals were housed in sterile conditions at $19-21^{\circ} \mathrm{C}$, with a relative humidity of 50-60\%, ad libitum intake of water and food and under 12-h of light/dark cycle. The present study was performed in strict accordance with the recommendations given in the Guide for the Care and Use of Laboratory Animals of the National Institutes of Health. The animal use protocol was reviewed and approved by the Institutional Animal Care and Use Committee (IACUC) of Xinxiang Medical University. 
Main instruments and reagents. DMEM/F12 medium and trypsin were purchased from Sigma-Aldrich; Merck KGaA, (Darmstadt, Germany). Fetal bovine serum (FBS; Gibco ${ }^{\mathrm{TM}}$ ) was purchased from Thermo Fisher Scientific, Inc. (Waltham, MA, USA). Penicillin-streptomycin solution was purchased from Beijing Dingguo Biotechnology Co., Ltd. (Beijing, China). A HERAcell 150i $\mathrm{CO}_{2}$ incubator and an MK3 microplate reader were purchased from Thermo Fischer Scientific, Inc. Monoclonal antibodies raised against $\alpha$-synuclein, cleaved caspase-3, Akt and phosphorylated (p)-Akt were purchased from R\&D Systems, Inc. (Minneapolis, MN, USA). A bicinchoninic acid (BCA) protein quantification kit was purchased from Shanghai Yi Sheng Biotechnology Co., Ltd. (Shanghai, China). Tumor necrosis factor- $\alpha$ (TNF- $\alpha$ ) and interleukin- $1 \beta$ (IL-1 $\beta$ ) detection kits were purchased from Shanghai Bai Rui Biotechnology Co., Ltd. (Shanghai, China). A nitric oxide (NO) content detection kit was purchased from Applygen Technologies, Inc. (Beijing, China).

Primary isolation and culture of microglia and primary neurons. The mice, within $24 \mathrm{~h}$ of birth, were sacrificed prior to subsequent investigations, and the numbers of mice that were sacrificed were dependent on the requirements for each individual set of experiments. The cerebral cortex vessels were removed and placed in DMEM/F12 medium, after having been treated with $75 \%$ alcohol. Following excision of the brain tissues, $10 \mathrm{ml} 0.125 \%$ trypsin was added, and the samples were placed in a water bath at $37^{\circ} \mathrm{C}$ to perform a rapid digestion reaction for $5 \mathrm{~min}$. FBS was then added to terminate the digestion reaction, and the samples were placed at room temperature for $3 \mathrm{~min}$; tissue precipitation was observed in the lower layer, and the supernatant was transferred to EP tubes by filtering through a $70 \mu \mathrm{m}$ filter. The filtered solution was centrifuged at $168 \mathrm{x} \mathrm{g}$ for $10 \mathrm{~min}$ at $25^{\circ} \mathrm{C}$, and the supernatant was then discarded. DMEM/F12 medium containing 15\% FBS and $100 \mathrm{U} / \mathrm{ml}$ penicillin-streptomycin was added to the pellet and the cells suspension was transferred into a cell culture flask coated with poly-d-lysine for incubation in a $5 \% \mathrm{CO}_{2}$ incubator at $37^{\circ} \mathrm{C}$ for $24 \mathrm{~h}$ following by replacement of fresh cell culture. After the cells in the flask were cultured for 10 days and incubated with agitation for $60 \mathrm{~min}$, the medium was removed and the cells were washed with PBS. The cells were then collected and seeded into a 6 -well cell culture plate. A total of $3 \times 10^{5}$ cells were added to each well. Following incubation for $30 \mathrm{~min}$, the adherent cells were microglia cells; following 5 days of culture, it was possible to collect the primary microglia.

Following sieving, the filtrate was centrifuged at $300 \mathrm{x} \mathrm{g}$ at $4^{\circ} \mathrm{C}$ for $10 \mathrm{~min}$, and the precipitated cells were suspended in DMEM/F12 cell culture medium containing 10\% FBS, 2\% B27 and $100 \mathrm{U} / \mathrm{ml}$ penicillin-streptomycin solution. Cells were subsequently inoculated into a lysine-coated cell flask, and following $24 \mathrm{~h}$, the medium was replaced by the same medium lacking FBS. Primary neurons were obtained three days after isolation and culture.

Experimental grouping. The cells were divided into a control group, a CCL2 group, an $\alpha$-synuclein group and a CCL2 plus $\alpha$-synuclein group. In the control group, the cells were treated with an identical amount of PBS, whereas the cells in the CCL2 group were cultured in medium containing CCL2
$(1.632 \mathrm{mg} / \mathrm{ml})$ at a concentration of $0.05 \mathrm{ng} / \mu \mathrm{l}$; cells in the $\alpha$-synuclein group were treated with medium containing $\alpha$-synuclein $(1.120 \mathrm{mg} / \mathrm{ml})$ at a concentration of $0.2 \mathrm{ng} / \mu \mathrm{l}$; and cells in the CCL2 plus $\alpha$-synuclein group were cultured in medium containing $0.05 \mathrm{ng} / \mu \mathrm{l}$ CCL 2 and $0.2 \mathrm{ng} / \mu \mathrm{l} \alpha$-synuclein.

MTT detection of cell proliferation. Washed cells were seeded into 96-well cell culture plates, and $100 \mu \mathrm{l}$ cell suspension was added to each well. The cells were incubated at $37^{\circ} \mathrm{C}$ in a $5 \% \mathrm{CO}_{2}$ incubator for $24 \mathrm{~h}$. The medium was replaced as described in the Primary isolation and culture of microglia and neurons section above, $20 \mu \mathrm{l}$ MTT solution $(5 \mathrm{mg} / \mathrm{ml})$ was added to each well, and the cells were further incubated in the $\mathrm{CO}_{2}$ incubator for $4 \mathrm{~h}$, after which time $150 \mu \mathrm{l}$ dimethyl sulfoxide solution was added. After allowing the reaction to proceed for $10 \mathrm{~min}$, the absorbance values per well were measured at $450 \mathrm{~nm}$ using a microplate reader.

Detection of NO by the Griess method. NO gives rise to nitrite $\left(\mathrm{NO}^{2-}\right)$ anions in an aqueous environment, although in an acidic environment, $\mathrm{NO}^{2-}$ may react with sulfonamide compounds to form diazonium salts, as well as coupling with naphthylethylenediamine (Griess reagent). The more that these compounds are generated, the higher is the absorbance measured at $540 \mathrm{~nm}$, reflecting the higher NO content. Cells in each group were collected, and the cells were cultured for $24 \mathrm{~h}$. The NO content in the cell culture medium was detected by following the protocol provided with the NO content detection kit.

Determination of the TNF- $\alpha$ and IL-1 $\beta$ content by the ELISA method. Cells in each group were collected and cultured in the incubator at $37^{\circ} \mathrm{C}$ for $24 \mathrm{~h}$. The levels of inflammatory factors in the cell culture medium were measured using an ELISA kit of TNF- $\alpha$ (cat. no. T04140; Groundwork Biotechnology Diagnosticate, Ltd., San Diego, USA) or IL-1 $\beta$ (cat. no. V006-10; Groundwork Biotechnology Diagnosticate, Ltd., San Diego, CA, USA). The absorbance of each well at $450 \mathrm{~nm}$ was measured using a microplate reader.

$\alpha$-Synuclein levels in cells detected by western blot analysis. Cells in each group were collected and cultured after $24 \mathrm{~h}$. The medium was discarded. The cells were incubated with lysate for $10 \mathrm{~min}$, and the lysate was then transferred into centrifuge tubes and centrifuged at $168 \mathrm{xg}$ for $10 \mathrm{~min}$ at $4^{\circ} \mathrm{C}$. The supernatant was transferred into the EP tube, and the extracted protein concentration was detected using a BCA protein quantification kit. The protein sample was subsequently mixed with loading buffer and boiled at $100^{\circ} \mathrm{C}$ for $5 \mathrm{~min}$. The denatured protein samples were added to the sample wells of an SDS-PAGE gel (10\%), and the initial voltage for electrophoresis was set at $90 \mathrm{~V}$. When the bromophenol blue was observed to have run into the edge of the stacking and removing gels, the voltage was adjusted to $120 \mathrm{~V}$ until the end of the electrophoresis was reached. The proteins (20 $\mu \mathrm{g} /$ well) loaded in the gel were electro-transferred onto a polyvinylidene difluoride (PVDF) membrane for $90 \mathrm{~min}$ at $4^{\circ} \mathrm{C}$. The PVDF membrane was sealed in $5 \%$ skimmed milk powder at $37^{\circ} \mathrm{C}$ for $90 \mathrm{~min}$, followed by reaction with the primary antibody-anti- $\alpha$-synuclein antibody (cat. no. ab138501; 1:500; $4^{\circ} \mathrm{C}$ incubation overnight; Abcam, 


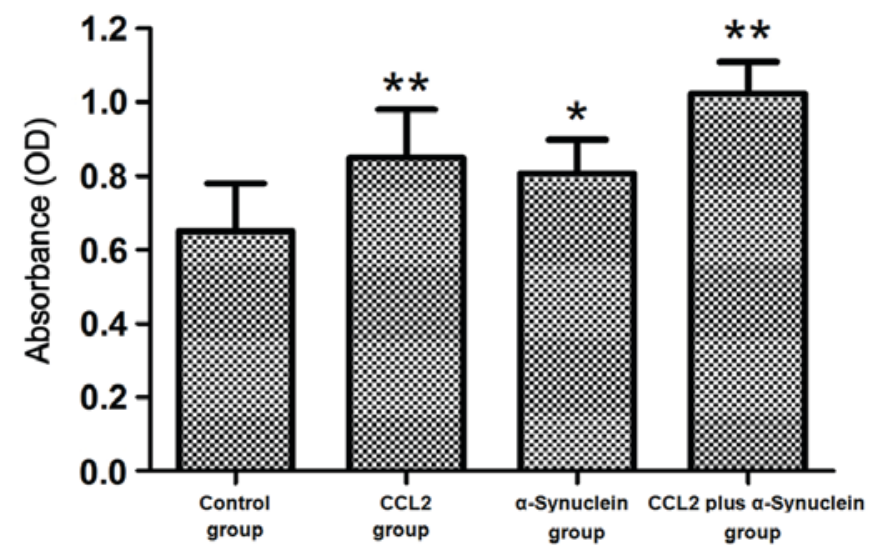

Figure 1. Microglia cell proliferation test results in the control, CCL2, $\alpha$-synuclein and CCL 2 plus $\alpha$-synuclein groups. " $\mathrm{P}<0.05$ vs. the control group ${ }^{* * *} \mathrm{P}<0.01$ vs. the control group. CCL2, chemokine CC ligand 2.

Cambridge, UK), followed by the secondary antibody-goat anti-rabbit IgG H\&L (HRP) $\left(37^{\circ} \mathrm{C}\right.$ incubation for $90 \mathrm{~min}$; cat. no. ab6721; $1: 1,000 ;$ Abcam). After the reaction was allowed to develop with the colour substrate using Visualizer ${ }^{\mathrm{TM}}$ Western Blot Detection kit (EMD Millipore, Billerica, MA, USA), the protein expression levels were analyzed, comparing against GAPDH as the internal reference protein.

Detection of apoptosis by flow cytometry. Cells in each group were cultured for $24 \mathrm{~h}$ according to the identical procedure as that described for culture of the microglial cells. Cell culture medium was added to the neurons for $24 \mathrm{~h}$, following which time the culture medium was discarded, the cells were treated with $0.125 \%$ trypsin, and following digestion, the mixture was centrifuged at $300 \mathrm{x} \mathrm{g}$ at $4^{\circ} \mathrm{C}$ for $5 \mathrm{~min}$. The supernatant was then discarded, the cells were washed once in PBS, binding buffer was added, and the cells were suspended and mixed, adjusting the concentration of the cells to $3 \times 10^{6}$ cells $/ \mathrm{ml}$. A total of $5 \mu \mathrm{l}$ of Annexin $\mathrm{V}$ and propidium iodide (PI) were added to each $100 \mu \mathrm{l}$ cell suspension, and the reactions were allowed to proceed at room temperature for $10 \mathrm{~min}$. Apoptosis was detected using flow cytometry FACSARIA III (BD) with FlowJo 10 (LLC, Ashland, OR, USA) software using a Dead Cell Apoptosis kit (cat. no. V13242; Invitrogen; Thermo Fisher Scientific, Inc.).

Detection of the levels of cleaved caspase-3, Akt and p-Akt in neurons by western blotting. Again, cells in each group were cultured for $24 \mathrm{~h}$ according to the identical procedure as that described for culture of the microglial cells. Cell culture medium was added to the neurons for $24 \mathrm{~h}$, after which time the culture medium was discarded and the proteins in the neurons were collected. The levels of cleaved caspase-3, Akt and p-Akt in the neurons was detected by western blotting, as described above.

Statistical analysis. Experimental data were analysed using IBM SPSS statistics software, version 22 (IBM Corps, Armonk, NY, USA). Data were expressed as the mean \pm standard deviation $(\bar{x} \pm \mathrm{s})$. Comparisons between two of the groups were made using the t-test. One-way analysis of variance was used to compare multiple groups. Multiple comparisons between the groups were performed using Tukey's post-hoc test. $\mathrm{P}<0.05$ and $\mathrm{P}<0.01$ were considered to indicate a statistically significant difference.

\section{Results}

Cell proliferation. The proliferation of cultured microglia cells was detected by MTT assay after the cells were treated with $0.05 \mathrm{ng} / \mu \mathrm{l}$ CCL2, $0.2 \mathrm{ng} / \mu 1 \alpha$-synuclein and $0.05 \mathrm{ng} / \mu 1$ CCL2 plus $0.2 \mathrm{ng} / \mu \mathrm{l} \alpha$-synuclein. The results demonstrated that proliferation of the $\alpha$-synuclein cells was significantly higher compared with that of the control group $(\mathrm{P}<0.05)$. Furthermore, proliferation of the cells in the CCL2 and CCL2 plus $\alpha$-synuclein groups was significantly higher compared with that in the control group $(\mathrm{P}<0.01$; Fig. 1).

Detection of the levels of NO,TNF- $\alpha$ and $I L-1 \beta$. After $24 \mathrm{~h}$ culture, the medium for each experimental group was collected, and the levels of NO, TNF- $\alpha$ and IL-1 $\beta$ in the supernatant were subsequently measured. The results showed that the levels of $\mathrm{NO}$ in the CCL2, $\alpha$-synuclein and CCL2 plus $\alpha$-synuclein groups were significantly higher compared with that in the control group $(\mathrm{P}<0.01)$. In addition, the levels of TNF- $\alpha$ and IL-1 $\beta$ in the CCL2 and $\alpha$-synuclein groups were significantly higher compared with that in the control group $(\mathrm{P}<0.05)$. The levels of TNF- $\alpha$ and IL- $1 \beta$ in the CCL2 plus $\alpha$-synuclein group were significantly higher compared with that in the control group ( $\mathrm{P}<0.01$; Fig. 2$)$.

$\alpha$-Synuclein level in cells. The cells in each group following $24 \mathrm{~h}$ culture were collected, and total protein was then extracted. The levels of $\alpha$-synuclein were detected using western blot analysis. The results demonstrated that, compared with the control group, there was no obvious increase in the expression level of $\alpha$-synuclein for the $\alpha$-synuclein group. However, the levels of $\alpha$-synuclein in the CCL2 and CCL2 plus $\alpha$-synuclein groups were significantly higher compared with that in the control group $(\mathrm{P}<0.01$; Fig. 3$)$.

Neuronal apoptosis. After the cells in each group were cultured for $24 \mathrm{~h}$, microglia cells were added to the neurons. Cells undergoing apoptosis were subsequently detected using flow cytometric analysis, and the level of cleaved caspase- 3 in the neurons after $24 \mathrm{~h}$ was detected by western blotting. The results showed that the apoptotic rate of the CCL2, $\alpha$-synuclein and CCL2 plus $\alpha$-synuclein groups was significantly higher compared with that of the control group $(\mathrm{P}<0.01)$. Similarly, the levels of cleaved caspase- 3 protein in the CCL2, $\alpha$-synuclein and CCL2 plus $\alpha$-synuclein groups were significantly higher compared with that in control group ( $\mathrm{P}<0.01$; Fig. 4).

Levels of Akt and p-Akt in the cells determined by western blot analysis. Following culture for $24 \mathrm{~h}$, the microglia cell culture medium was added to the neurons. The levels of Akt and p-Akt were then detected by western blotting. The results demonstrated that no significant differences were identified in the levels of Akt protein in the CCK2, $\alpha$-synuclein and CCL2 plus $\alpha$-synuclein groups compared with the control group ( $\mathrm{P}>0.05$ ). However, the levels of $\mathrm{p}$-Akt protein in the CCL2, $\alpha$-synuclein 

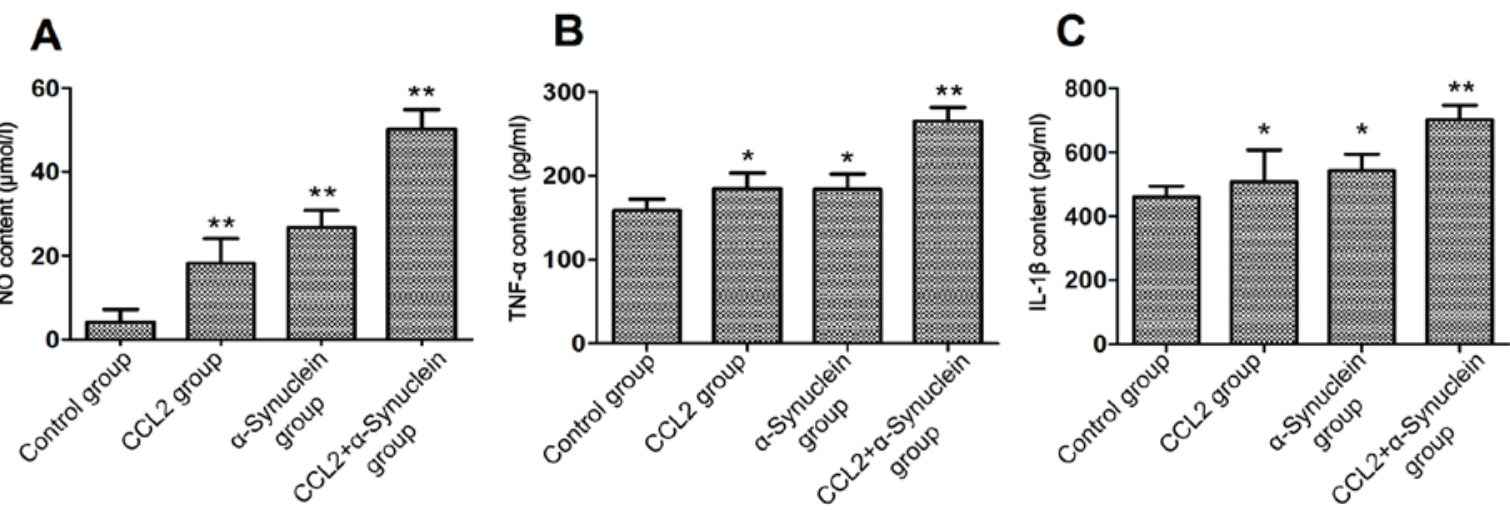

Figure 2. NO content and TNF- $\alpha$, IL-1 $\beta$ detection in the control, CCL2, $\alpha$-synuclein and CCL2 plus $\alpha$-synuclein groups. Respectively, the panels demonstrate: (A) NO content; (B) TNF- $\alpha$ content and (C) IL-1 $\beta$ content. ${ }^{*} \mathrm{P}<0.05,{ }^{* *} \mathrm{P}<0.01$ vs. the control group. CCL2, chemokine CC ligand 2; NO, nitric oxide; TNF- $\alpha$, tumor necrosis factor- $\alpha$; IL-1 $\beta$, interleukin- $1 \beta$.
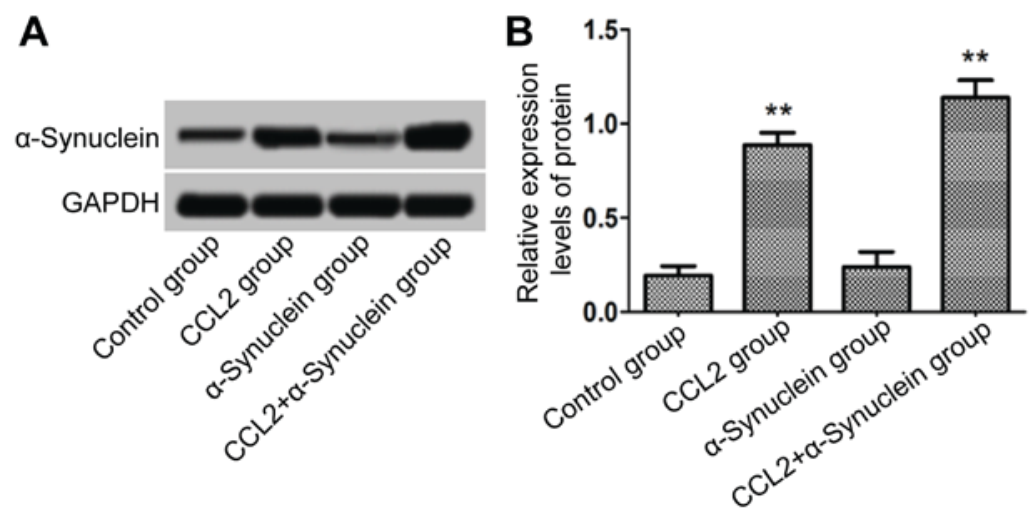

Figure 3. $\alpha$-synuclein level in the cells of the control, CCL2, $\alpha$-synuclein and CCL2 plus $\alpha$-synuclein groups. (A) The results of the western blot analysis are presented. (B) The relative protein expression levels are presented. ${ }^{* *} \mathrm{P}<0.01$ vs. the control group. CCL2, chemokine CC ligand 2.

and CCL2 plus $\alpha$-synuclein groups were significantly lower compared with those in the control group $(\mathrm{P}<0.01$; Fig. 5$)$.

\section{Discussion}

Microglia originate in the neuroectoderm. When the central nervous system becomes damaged, microglia are able to engulf harmful substances in the nervous system (9). In mature brain tissue, microglia are in a quiescent state, and are able to sense abnormal pathological changes in the surrounding environment. Microglia are also able to promote neuronal proliferation, and to protect the brain's tissue structure. Microglia activation may lead to the secretion of a variety of immune factors and NO (10). On the one hand, NO has a role in the killing of pathogens; on the other hand, neurons themselves may exert a certain toxic effect. A previous study has demonstrated that neurodegenerative diseases are associated with abnormal activation of the microglia, leading to the production of inflammatory factors, which, in turn, have a certain toxicity for the nervous system (11).

The gene for $\alpha$-synuclein is located on chromosome 4 and contains 7 exons (12). $\alpha$-Synuclein protein is widely expressed in various structures of the brain, including the cerebral cortex, neuronal synapse, hippocampus, and so forth, and these are involved in the processes of normal synaptic signal transmission. Under normal circumstances, microglia may engulf and degrade $\alpha$-synuclein protein (13). However, when the microglia are abnormally activated, their ability to engulf and degrade $\alpha$-synuclein protein decreases, thus leading to a large accumulation of $\alpha$-synuclein proteins that produce neurotoxicity (14). A previous study has shown that the overexpression of $\alpha$-synuclein in the bodies of animals leads to abnormal activation of the microglia, thereby leading to an increased rate of neuronal death (15). Upon stimulation of cultured microglia in vitro with $\alpha$-synuclein protein, microglia activation was demonstrated to be increased, leading to the production of a large number of inflammatory factors and NO (16). In the present study, $\alpha$-synuclein was used to stimulate the microglia cells, and the results demonstrated that the microglia proliferation capacity was increased; also, the secretion of NO, TNF- $\alpha$ and IL- $1 \beta$ in the cells was increased, results which were consistent with those reported previously.

CCL2 is a monocyte chemotactic factor. Recent studies have shown that CCL2 expression is increased in the peripheral blood and cerebrospinal fluid of patients with neurodegenerative diseases, whereas the activity of microglia upon inhibition of CCL2 expression was found to decrease as the cognitive function of the biological organism was being restored $(17,18)$. CCL2 was also shown to be involved in the inflammatory response of the central nervous system, and was associated with the body's NO content and oxygen free radical levels (19). Previous studies have demonstrated that $0.05 \mathrm{ng} / \mu 1 \mathrm{CCL} 2$ may significantly 

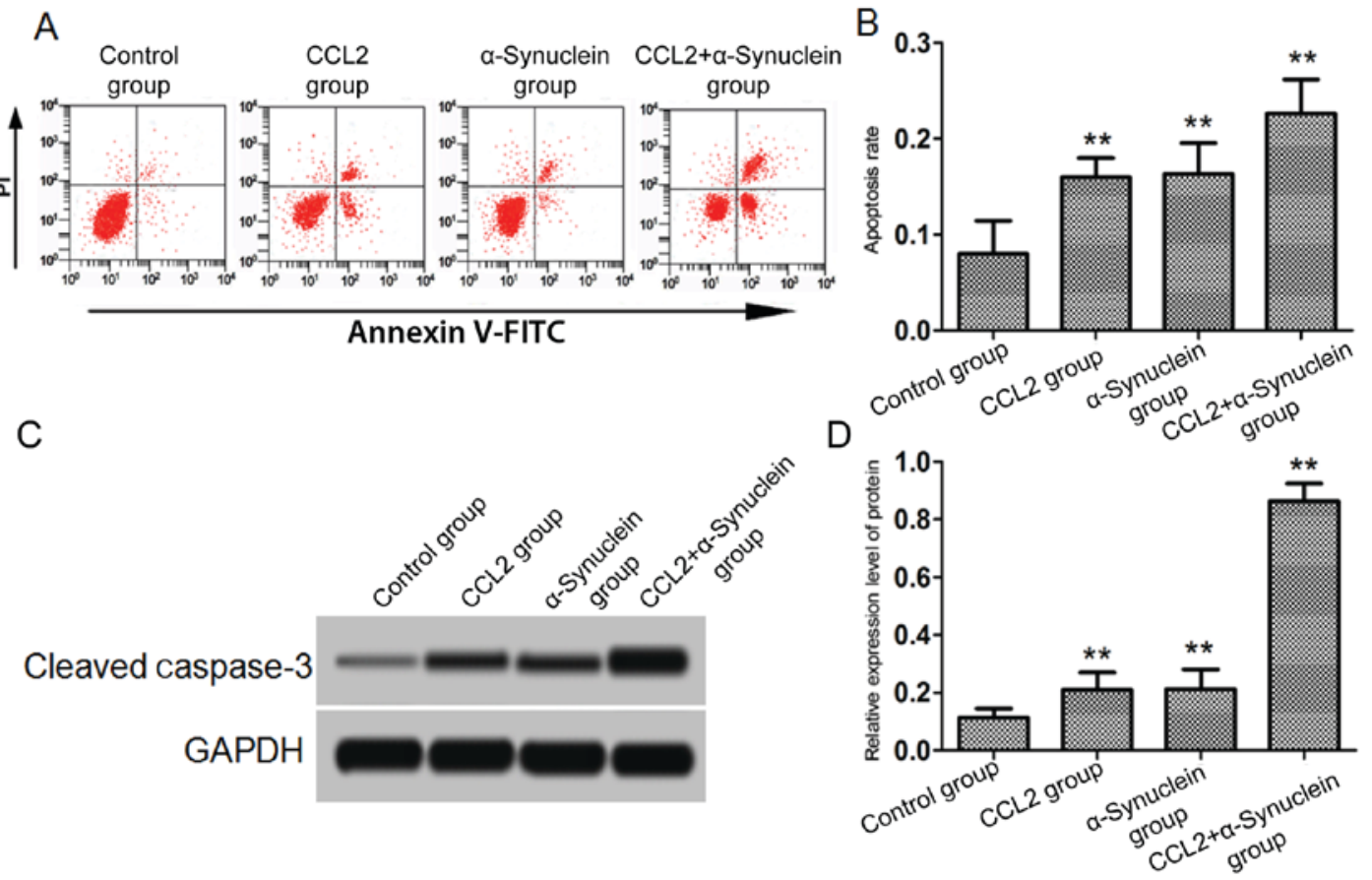

Figure 4. Neuronal apoptosis in the cells of the control, CCL2, $\alpha$-synuclein and CCL2 plus $\alpha$-synuclein groups. The results of the (A) flow cytometric analysis, (B) apoptotic rate determination, (C) and western blot analysis experiments are presented. (D) Quantitative analysis of the relative protein expression levels presented (in C). ${ }^{* *} \mathrm{P}<0.01$ vs. the control group. CCL2, chemokine CC ligand 2.

A

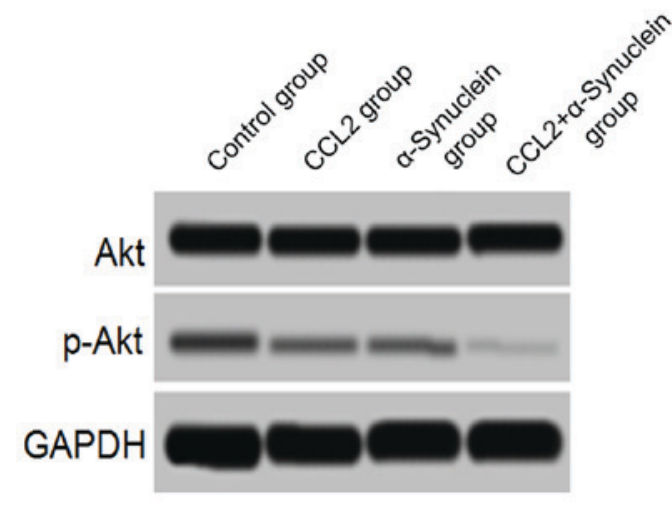

B

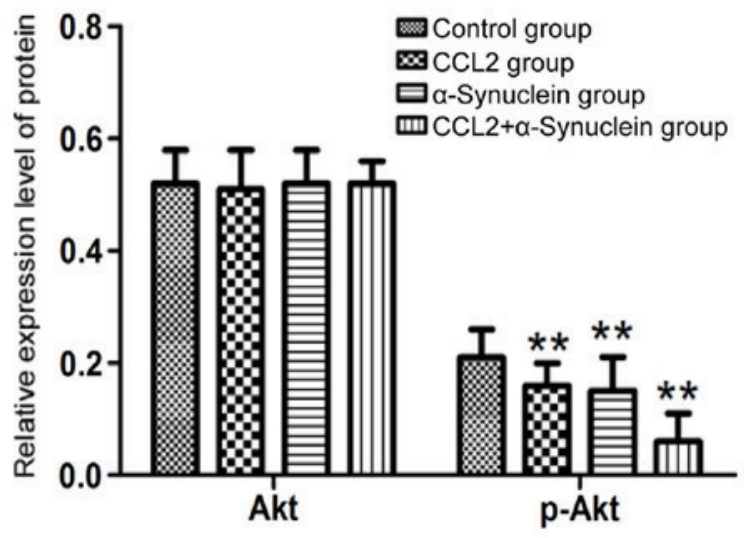

Figure 5. Akt, and p-Akt levels in cells of the control, CCL2, $\alpha$-synuclein and CCL2 plus $\alpha$-synuclein groups. (A) The results of the western blot analysis are demonstrated. (B) The relative protein expression levels are presented. ${ }^{* *} \mathrm{P}<0.01$ vs. the control group. CCL2, chemokine CC ligand 2.

promote the proliferation of microglia (20). In the present study, microglia were treated with $0.05 \mathrm{ng} / \mu \mathrm{l}$ CCL2 protein, and it was demonstrated that CCL2 could promote the proliferation of microglia and the secretion of NO, TNF- $\alpha$ and IL- $1 \beta$.

In order to study further the effect of CCL2 on neurons, the primary neurons were cultured in vitro and treated with microglia culture medium containing CCL2 and $\alpha$-synuclein. The results demonstrated that the CCL2/ $\alpha$-synuclein-treated microglia culture mixture was able to promote neuronal apoptosis. Furthermore, the rate of neuronal apoptosis was found to increase following treatment with a combination of CCL2 and $\alpha$-synuclein. Additionally, the expression of cleaved caspase-3 and other components of the Akt signaling pathway in neurons were detected: The level of cleaved caspase-3 protein was increased whereas that of $\mathrm{p}$-Akt decreased, suggesting that
CCL2 promoted the proliferation of $\alpha$-synuclein-induced microglia, thus causing neuronal apoptosis which may be associated with the Akt signaling pathway.

In conclusion, the present study has shown that CCL2 is able to promote the proliferation of $\alpha$-synuclein-induced microglia, via which the secretion of inflammatory factors and NO by microglia is also promoted, thereby inducing neuronal apoptosis. The pro-apoptotic mechanisms may be associated with the Akt signaling pathway. The results thus obtained have laid a foundation for further study of the pathogenesis of neurodegenerative diseases.

\section{Acknowledgements}

Not applicable. 


\section{Funding}

The present study was supported by the Key Science and Technology Project of Henan Province, China (grant no. 172102310685$)$.

\section{Availability of data and materials}

The datasets used and analyzed during the current study are available from the corresponding author on reasonable request.

\section{Authors' contributions}

BY made substantial contributions to the design of the present study. LZ, PM, QG, LS and LW performed the experiments of cell culture, MTT, detection of $\mathrm{NO}$ and interpreted the data. LZ, QG, LS and LM performed the experiments of ELISA and western blotting. All authors read and approved the final manuscript.

\section{Ethics approval and consent to participate}

The present study was performed in strict accordance with the recommendations given in the Guide for the Care and Use of Laboratory Animals of the National Institutes of Health. The animal use protocol was reviewed and approved by the Institutional Animal Care and Use Committee (IACUC) of Xinxiang Medical University.

\section{Patient consent for publication}

Not applicable.

\section{Competing interests}

The authors declare they have no competing interests.

\section{References}

1. Glebov K, Löchner M, Jabs R, Lau T, Merkel O, Schloss P, Steinhäuser C and Walter J: Serotonin stimulates secretion of exosomes from microglia cells. Glia 63: 626-634, 2015.

2. Wang Y, Gao H, Zhang W, Zhang W and Fang L: Thymoquinone inhibits lipopolysaccharide-induced inflammatory mediators in BV2 microglial cells. Int Immunopharmacol 26: 169-173, 2015.

3. Kim M, Choi SY, Lee P and Hur J: Neochlorogenic acid inhibits lipopolysaccharide-induced activation and pro-inflammatory responses in BV2 microglial cells. Neurochem Res 40: 1792-1798, 2015.

4. Chun E, Lavoie S, Michaud M, Gallini CA, Kim J, Soucy G, Odze R, Glickman JN and Garrett WS: CCL2 promotes colorectal carcinogenesis by enhancing polymorphonuclear myeloid-derived suppressor cell population and function. Cell Rep 12: 244-257, 2015

5. Tsaur I, Rutz J, Makarević J, Juengel E, Gust KM, Borgmann H, Schilling D, Nelson K, Haferkamp A, Bartsch G and Blaheta RA CCL2 promotes integrin-mediated adhesion of prostate cancer cells in vitro. World J Urol 33: 1051-1056, 2015.
6. Mbefo MK, Fares MB, Paleologou K, Oueslati A, Yin G, Tenreiro S, Pinto M, Outeiro T, Zweckstetter M, Masliah E and Lashuel H: Parkinson disease mutant E46 K enhances $\alpha$-synuclein phosphorylation in mammalian cell lines, in yeast and in vivo. J Biol Chem 290: 9412-9427, 2015.

7. Moree B, Yin G, Lázaro DF, Munari F, Strohäker T, Giller K, Becker S, Outeiro TF, Zweckstetter M and Salafsky J: Small molecules detected by second-harmonic generation modulate the conformation of monomeric $\alpha$-synuclein and reduce its aggregation in cells. J Biol Chem 290: 27582-27593, 2015.

8. Kempuraj D, Thangavel R, Yang E, Pattani S, Zaheer S, Santillan DA, Santillan MK and Zaheer A: Dopaminergic Toxin 1-Methyl-4-Phenylpyridinium, proteins $\alpha$-synuclein and glia maturation factor activate mast cells and release inflammatory mediators. PLoS One 10: e0135776, 2015.

9. Shinozaki Y, Shibata K, Yoshida K, Shigetomi E, Gachet C, Ikenaka K, Tanaka KF and Koizumi S: Transformation of Astrocytes to a neuroprotective phenotype by microglia via P2Y1 receptor downregulation. Cell Rep 19: 1151-1164, 2017.

10. Mangino G, Famiglietti M, Capone C, Veroni C, Percario ZA, Leone S, Fiorucci G, Lülf S, Romeo G, Agresti C, et al: HIV-1 myristoylated Nef treatment of murine microglial cells activates inducible nitric oxide synthase, NO2 production and neurotoxic activity. PLoS One 10: e0130189, 2015.

11. Cox DJ, Field RH, Williams DG, Baran M, Bowie AG, Cunningham $\mathrm{C}$ and Dunne A: DNA sensors are expressed in astrocytes and microglia in vitro and are upregulated during gliosis in neurodegenerative disease. Glia 63: 812-825, 2015.

12. Van der Perren A, Macchi F, Toelen J, Carlon MS, Maris M, de Loor H, Kuypers DR, Gijsbers R, Van den Haute C, Debyser Z and Baekelandt V: FK506 reduces neuroinflammation and dopaminergic neurodegeneration in an $\alpha$-synuclein-based rat model for Parkinson's disease. Neurobiol Aging 36: 1559-1568, 2015.

13. Tang Y and Le W: Differential roles of M1 and M2 microglia in neurodegenerative diseases. Mol Neurobiol 53: 1181-1194, 2016.

14. Harms AS, Cao S, Rowse AL, Thome AD, Li X, Mangieri LR, Cron RQ, Shacka JJ, Raman C and Standaert DG: MHCII is required for $\alpha$-synuclein-induced activation of microglia, CD4 $\mathrm{T}$ cell proliferation and dopaminergic neurodegeneration. J Neurosci 33: 9592-9600, 2013.

15. Daher JP, Volpicelli-Daley LA, Blackburn JP, Moehle MS and West AB: Abrogation of $\alpha$-synuclein-mediated dopaminergic neurodegeneration in LRRK2-deficient rats. Proc Natl Acad Sci USA 111: 9289-9294, 2014.

16. Codolo G, Plotegher N, Pozzobon T, Brucale M, Tessari I, Bubacco L and de Bernard M: Triggering of inflammasome by aggregated $\alpha$-synuclein, an inflammatory response in synucleinopathies. PLoS One 8: e55375, 2013.

17. Kim RY, Hoffman AS, Itoh N, Ao Y, Spence R, Sofroniew MV and Voskuhl RR: Astrocyte CCL2 sustains immune cell infiltration in chronic experimental autoimmune encephalomyelitis. J Neuroimmunol 274: 53-61, 2014.

18. Kempuraj D, Thangavel R, Fattal R, Pattani S, Yang E, Zaheer S, Santillan DA, Santillan MK and Zaheer A: Mast cells release chemokine CCL2 in response to parkinsonian toxin 1-Methyl-4-Phenyl-Pyridinium (MPP+). Neurochem Res 41: 1042-1049, 2016

19. Bose $\mathrm{S}$ and Cho J: Role of chemokine CCL2 and its receptor CCR2 in neurodegenerative diseases. Arch Pharm Res 36: 1039-1050, 2013.

20. Gómez-Nicola D, Schetters ST and Perry VH: Differential role of CCR2 in the dynamics of microglia and perivascular macrophages during prion disease. Glia 62: 1041-1052, 2014.

This work is licensed under a Creative Commons Attribution-NonCommercial-NoDerivatives 4.0 International (CC BY-NC-ND 4.0) License. 